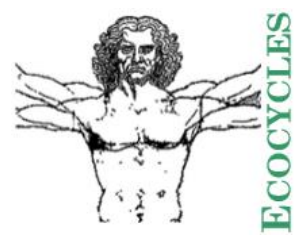

Ecocycles, Vol. 7, No. 2, pp. 35-45 (2021)

DOI: $10.19040 /$ ecocycles.v7i2.210

\title{
REVIEW
}

\section{Microalgae cultivation integrated into agro-industrial wastewater treatment}

\author{
${ }^{1}$ David Pacha-Herrera, ${ }^{2}$ Péter Tamás Nagy, ${ }^{2}$ Tamás Magyar \\ ${ }^{1}$ Department of Environmental Engineering, University of Debrecen, Hungary \\ ${ }^{2}$ Institute of Water and Environmental Management, University of Debrecen, Hungary \\ Corresponding author: nagypt@agr.unideb.hu
}

\begin{abstract}
The world demands more and more energy due to the continuous population increase. In parallel, high organic and nutrient contents of wastewater streams are generated from anthropogenic activities like urbanization, industrialization, and agricultural practices. The continuous discharge of these wastewater streams into water bodies has been considered responsible for oxygen depletion and eutrophication in the environment. Integrating microalgae cultivation into wastewater treatment can be a promising solution to produce renewable energy while removing pollutants. In contrast to several review articles published about microalgae cultivation on different wastewater streams, the current review is focusing mainly on microalgaebased wastewater treatment on agricultural waste streams. Hence, first of all, the main characteristics of different agricultural streams will be described, then microalgal consortia cultivation, as well as monoculture strains, will be evaluated. Moreover, the photobioreactor systems for agricultural wastewater treatment will also be summarized. Finally, harvesting methods for microalgae recovery will be presented.
\end{abstract}

Keywords - microalgae cultivation, agro-industrial wastewater, characteristics, photobioreactor, harvesting.

\section{INTRODUCTION}

The growing world demands for energy and the increase in waste generation have the same origin: the growth of the world population. Although the annual growth rate of the world population has shown a decrease since its peak in 1968 , the projections estimate that the world population will continue to grow at a slower rate and stabilize around 11 billion by the end of this century (United Nations, 2019; Roser et al., 2019). Hence, considerable efforts have been focused on the mitigation of the negative impacts on the environment of the waste generation, especially on wastewater production, and the worldwide consumption of energy (Chen et al., 2013; Posadas et al., 2017; Alam and Wang, 2019; Maulana et al., 2019). Based on both goals, microalgae cultivation has been evaluated as a potential source of renewable energy (Chiu et al., 2014; Komolafe et al., 2014; Shchegolkova et al., 2018; Alam and Wang, 2019; Nguyen et al., 2019; Zabed et al., 2020) and pollutant removal agent (Caporgno et al., 2015; Novoveská et al., 2016; Gonçalves et al., 2017; Paddock et al., 2020; Shahid et al., 2020; Al-Jabri et al., 2021) in recent years.

In general, microalgae term refers to a diverse group of photosynthetic aquatic organisms that englobes unicellular or multicellular eukaryotes (red, green, brown, and diatoms microalgae) and prokaryote organisms called cyanobacteria or blue-green algae (Al Darmaki et al., 2012; De Freitas Coêlho et al., 2019; Molinuevo-Salces et al., 2019) due to their physiological characteristics and photosynthetic capability (De Freitas Coêlho et al., 2019). The photosynthetic capability of microalgae allows them to fix inorganic carbon $\left(\mathrm{CO}_{2}\right)$ from the emissions of anthropogenic activities through the so-called Calvin cycle, using light as the energy source to produce biomass, while is released $\mathrm{O}_{2}$ into the atmosphere (Molinuevo-Salces et al., 2019). However, the culture of microalgae is restricted to the use of an aquatic medium rich in macro and micronutrients, especially carbon, 
nitrogen, and phosphorus content (Chen et al., 2013; Cheah et al., 2016; Gonçalves et al., 2017); since they have demonstrated high nutrient assimilation for their cellular growth (biomass production). Rawat et al. (2013) and Khan et al. (2018) described a biomass production of $1 \mathrm{~kg}$ per each $1.83 \mathrm{~kg} \mathrm{CO}_{2}$ fixed; furthermore, biomass content analysis showed that a microalgae cell could contain between $30-60 \%$ of carbohydrates and $20-40 \%$ of lipids, making microalgae biomass valuable as an alternative renewable source to produce bioethanol and biodiesel, respectively.

Due to the high organic and nutrient content of wastewater streams from anthropogenic activities like urbanization, industrialization, and agricultural practices and their continuous discharge into water bodies (Cheah et al., 2016; Gupta et al., 2019; Al-Jabri et al., 2021), they have been considered to be responsible for oxygen depletion (Cheah et al., 2016) and eutrophication (Cheah et al., 2016; Umamaheswari, J Shanthakumar, 2016; Li et al., 2019). However, this characteristic made these streams the ideal source media for microalgae growth (Al Darmaki et al., 2012). Thus, microalgae in different wastewater streams have been evaluated within wastewater treatment systems because of their efficient removal of nutrients and heavy metals and the generation of biomass through $\mathrm{CO}_{2}$ fixation (Maulana et al., 2019). Researchers (Li et al., 2019; Paddock et al., 2020; Al-Jabri et al., 2021; Hussain et al., 2021) in this area have shown several benefits in its application over traditional wastewater treatment processes such as:

- the reduced cost of treating wastewaters because of microalgae biocapability to assimilate pollutants, and uptake nutrients;

- the removal of nutrients from the wastewater reduces the effect of eutrophication on water bodies and help to comply with standards regulation for stream discharge;

- microalgae biomass could be used as a valuable source for the production of biofuels;

- inorganic carbon fixation by the photosynthetic capacity of microalgae can reduce greenhouse gas emissions associated with fossil fuels.

Despite several review articles having been published about microalgae cultivation on different wastewater streams, the current review is focusing mainly on microalgae-based wastewater treatment on agricultural waste streams. Hence, the main characteristics of different agricultural streams will be described first of all, then microalgal consortia cultivation, as well as monoculture strains, will be evaluated. Moreover, the photobioreactor systems for agricultural wastewater treatment will also be summarized. Finally, harvesting methods for microalgae recovery will be presented.

\section{Agricultural WasteWater CHARACTERISTICS}

Like population growth, the consumption of energy or food has increased in the same proportion (Zabed et al., 2020). To produce food is necessary the use of a large amounts of water as raw material that at the end of the industrial processes will be discharged as wastewater (Li et al., 2019). The long-established nitrogen-to-phosphorus ratio of 16:1 ( $\mathrm{mol} / \mathrm{mol}$ ), high concentrations of organic carbon, and the abundance of nitrate, ammonium, minerals, and heavy metals make these wastewater streams the ideal medium for microalgae growth and the implementation of microalgaebased wastewater treatment systems ( $\mathrm{Al}$ Darmaki et al., 2012; Lowrey et al., 2015). However, the exorbitant content of ammonia concentration, suspended solid (SS), chroma and turbidity make it impossible for a direct application of microalgae-based wastewater treatment process. This is the reason why a pretreatment step should be performed such as anaerobic digestion (AD) or wastewater dilution ( $\mathrm{Li}$ et al., 2019). Some of the agricultural industries that produce wastewater with a high potential for microalgae cultivation include palm oil mill effluent (POME), swine, poultry, and aquaculture.

\subsection{Palm oil mill effluent (POME)}

The production of palm oil has increased continuously in the last years; for instance between 2010 and 2013 the production of coconut palm oil in Asia changed from 40.33 to 48.12 tons (Maulana et al., 2019). An important value when is considered that per each ton of palm oil produced, 5-7.5 tons of water are required; meanwhile, at the end of the processing is released 50 percent of this water as wastewater (Cheah et al., 2016). These waste streams are characterized by a high concentration of nitrogen, organics, and solids; furthermore, carbohydrates, proteins, nitrogenous compounds, and lipids have been found (Cheah et al., 2016). Upon discharge, POME streams have a brownish color with high temperature ranges $\left(80-90^{\circ} \mathrm{C}\right), \mathrm{pH}$ ranging from 4-5, biological oxygen demand (BOD), and chemical oxygen demand (COD) from 15,000-30,000 mg/L and 40,000-90,000 mg/L, respectively. The total suspended solid (TSS), total dissolved solid (TDS), and volatile suspended solids (VSS) content varies from 20,000-40,000 $\mathrm{mg} / \mathrm{L}, \quad 15,000-30,000 \mathrm{mg} / \mathrm{L}$, and 15,000-35,000 $\mathrm{mg} / \mathrm{L}$, respectively (Maulana et al., 2019). All these characteristics give a high pollutant profile to POME streams, therefore a further pre-treatment process is suggested before their microalgae-based wastewater treatment process (Cheah et al., 2016; Maulana et al., 2019).

\subsection{Swine wastewater}

Pig/pork meat is the second most-consumed animal product around the world after chicken/poultry consumption with a global pork production of around 118.8 million metric tons in 2018 (Nagarajan et al., 2019). Thus, the treatment of wastewater from this industry is highly important. It was estimated that 1,300 tons of wastewater is produced per year per pig on a small-scale pig farm (Zhang et al., 2017). Swine wastewaters are generated from the water used to clean the hog housing which contains pig excreta or manure, urine, and washing wastewater. As a result of the abovementioned, this wastewater stream has a higher content of ammonia from the urine and chemical/biological oxygen demand from manure (Sandefur et al., 2016; Nagarajan et al., 2019). Furthermore, these streams contain high content 
of antibiotics and heavy metals because both are added in the feed, but only $10-20 \%$ of them are uptake by the pigs $(\mathrm{Li}$ et al., 2007). Therefore, a pre-treatment process should also be established before a microalgae-based wastewater treatment process. Some other characteristics of these streams are a nitrogen concentration of $800-2,300 \mathrm{mg} / \mathrm{L}$, a phosphorus content of $50-230 \mathrm{mg} / \mathrm{L}$, a specific $\mathrm{N}: \mathrm{P}$ ratio of about 12-17; BOD value between 2,000-30,000 mg/L, and the presence of $\mathrm{Zn}$ and $\mathrm{Cu}$ that were excreted by pigs of 8.98 $\mathrm{mg} / \mathrm{L}$ and $63.58 \mathrm{mg} / \mathrm{L}$, respectively (Li et al., 2020).

\subsection{Poultry wastewater}

As same as pig/pork meat production, the production of chicken/poultry has increased in the last years. In 2019 the global production reached nearly 128 million metric tons, being this animal product the most consumed. Studies have reported that on average 20 liters of water per bird per year is needed in a typical processing facility (Avula et al., 2009); water that results from bird washing, cleaning, and waste conveying (Terán Hilares et al., 2021). Typically, poultry wastewater contains a mixture of manure, residual food particles, feathers, broken eggs, and wood-shaving, making it a high in organic matter, suspended solids load with a complex mixture of proteins, lipids, and nutrients that should be pre-treated before a microalgae-based wastewater treatment processing (Singh et al., 2011; Terán Hilares et al., 2021). Some characteristics of this specific waste streams are the following: nitrogen $(1,570 \mathrm{mg} / \mathrm{L})$, phosphorus $(154$ $\mathrm{mg} / \mathrm{L})$, potassium $(1,632 \mathrm{mg} / \mathrm{L})$ content (Singh et al., 2011); TSS of $77 \mathrm{mg} / \mathrm{L}$, BOD 1,136 mg/L, COD 1,482 mg/L, 6.03 pH and turbidity of 98 NTU (Terán Hilares et al., 2021).

\subsection{Aquaculture wastewater}

Aquaculture is one of the fastest-growing food industries, it is estimated that, in 2030, the global production will achieve around 93.2 million tons; nevertheless, the increase of this activity, also generates an increase in the production of wastewater (Guldhe et al., 2017; Hawrot-Paw et al., 2020). The wastewater of this sector contains feces, uneaten food, and possibly residues of medicines or chemicals used for cleaning purposes (Hawrot-Paw et al., 2020; Al-Jabri et al., 2021). This stream is rich in nutrients such as nitrates, ammonia, phosphates, and organic load (Guo et al., 2013; Guldhe et al., 2017). Thus, a pre-treatment process is needed before the microalgae-based wastewater treatment system is performed. Initial characteristics of this stream before treatment could have the following values: COD 96-362 $\mathrm{mg} / \mathrm{L}$, BOD $215.5 \mathrm{mg} / \mathrm{L}$, TSS $468.5 \mathrm{mg} / \mathrm{L}$, total nitrogen (TN), and total phosphorus (TP) content between 38.8-277.5 $\mathrm{mg} / \mathrm{L}, 1.1-39.3 \mathrm{mg} / \mathrm{L}$, respectively (Guldhe et al., 2017; Dong et al., 2019).

\section{MICROALGAE IN NUTRIENT REMOVAL}

Microalgae cultivation in diverse wastewater streams has been discussed by different scientific groups during the last decades, because of the dynamic growth of microalgae in highly polluted streams by organic matter, minerals, and even heavy metals (Cheah et al., 2016; Gonçalves et al., 2017; Al-Jabri et al., 2021). However, microalgae are a big group of organisms, and each species could have a different tolerance when cultivation in wastewater streams is talked about (Komolafe et al., 2014; Molinuevo-Salces et al., 2019). Thus, multiple investigations focus on determining the tolerance of different microalgae species in a particular wastewater, using monocultures or microalgae consortia.

\subsection{Microalgal pure strains}

Multiple microalgae genera have been evaluated to grow in different wastewater, however, in this review, we will focus just on microalgal strains that have been used in agroindustrial wastewaters. Even though, Chlorella, Scenedesmus, and Nitzschia have been identified as the most tolerant genera for growing in most of the wastewater streams (Molinuevo-Salces et al., 2019; Magyar et al., 2021); also, other species have shown good performance such as Microspora, Chroococcus limneticus, Cyanophyta cocal in microalgal-based fish processing wastewater treatment process. However, most previous studies have found the best performance on the utilization of Chlorella vulgaris cultivation on agro-industrial wastewater.

For instance, Wang et al. (2016) developed a new method to treat the wastewater from the piggery industry based on a previous pre-treatment stage of the stream with UV irradiation and gradual domestication, where C. vulgaris showed the best removal performance of TN and TP of $89.5 \%$ and $85.3 \%$, respectively. Terán- Terán Hilares et al. (2021) developed a new method for the treatment of poultry wastewater based on a pre-treatment with acid precipitation $(\mathrm{pH}=4)$ followed by $C$. vulgaris cultivation $(\mathrm{pH}=6)$ achieving the removal of $80 \%$ of COD in the first step and $83 \%$ of the remanent in the second step. However, also other Chlorella species have demonstrated similar uptaken capability, C. minutissima showed a removal of $88 \%$ and over $99 \%$, in total nitrogen and phosphorus, respectively in aquaculture wastewater (Hawrot-Paw et al., 2020). Also using aquaculture wastewater, Guldhe et al. (2017) obtained the removal efficiency of $75.56 \%$ for ammonium, $84.51 \%$ for nitrates, $73.35 \%$, and $7.88 \%$ for phosphates and COD respectively, in $C$. sorokiniana cultivation. Guo et al. (2013) demonstrated an average removal efficiency of TN and TP between $87-89 \%$ and $98-99 \%$, respectively, using the cultivation of Platymonas subcordiformis in aquaculture wastewater.

\subsection{Microalgal consortia}

The polyculture of photosynthetic organisms is a strategy that has been considered in the last years to improve the efficiency of the removal uptake, resistance to the presence of high pollution levels, the development of settleable systems, and at the same time solves the problem of maintaining pure cultures under wastewater treatment processes (Gonçalves et al., 2017; Shahid et al., 2020). However, not always cooperative interactions have been reported between different microalgae species; the excretion of secondary metabolites, also called allelochemicals that show the growth inhibition of some microalgae are the particular interest of different studies (Singh et al., 2011; Brantes et al., 2013; Gonçalves et al., 2017). For instance, a 
co-cultivation of $C$. sorokiniana, C. minutissima, and Scenedemus bijuga in a waste stream from poultry liter anaerobic digester, it was demonstrated a reduction in the nitrogen removal from $53 \mathrm{mg} / \mathrm{L}$ to $46 \mathrm{mg} / \mathrm{L}$ when is compared independent monoculture versus their polyculture (Singh et al., 2011). Notwithstanding, other studies have determined cooperative interactions between both genera Chlorella and Scenedemus; the removal of nitrogen (481 $\mathrm{mg} / \mathrm{L})$ and phosphorus $(31 \mathrm{mg} / \mathrm{L})$ from textile wastewater have been reported (Huy et al., 2018). Furthermore, Koreiviené et al. (2014) also reported that removal efficiencies range between 88.6-96.4\% for total nitrogen, and $99.7-99.9 \%$ for total phosphorus in municipal wastewater.

\subsection{Microalgal-bacterial consortia}

In recent decades, microalgal-bacteria interaction has been widely studied; therefore, is well known the symbiotic relationship between both organisms. In general, the photosynthetic capability of microalgae make the release of oxygen, $\mathrm{O}_{2}$ is dissolved in the water and used by aerobic bacteria who convert the organic matter into inorganic $\mathrm{CO}_{2}$, meanwhile, nitrates are converted into nitrites and ammonium by anaerobic bacteria, which is uptaken by microalgae to produce biomass rich in lipids, carbohydrates, and proteins (Molinuevo-Salces et al., 2019; Shahid et al., 2020). However, microalgae-bacteria interaction is not just limited to the nutrient exchange; also microalgae can provide habitat for bacteria growth, and release some antibacterial metabolites to the growth inhibition of pathogen species such as Vibrio cholerae (Gonçalves et al., 2017; Molinuevo-Salces et al., 2019). Moreover, microalgae-bacteria interactions can result in the assimilation of heavy metals because of the negatively charged groups contained in the carbohydrates and exopolysaccharides of the bacteria and microalgae cell surface (Molinuevo-Salces et al., 2019).

About the improvement in nutrient assimilation, several studies have reported an increased level of nitrogen, phosphorus, and other nutrients uptake by this type of consortia. For example, the cultivation of Chlorella sorokiniana with prokaryotic organism microbiome resulted in the removal range of TN (34-67\%), COD (14-60\%) in anaerobic digestate effluent (Paddock et al., 2020). Similarly, Chlorella and Proteobacteria removed $72 \%$, $100 \%$, and $83 \%$ of $\mathrm{TN}, \mathrm{TP}$, and $\mathrm{Zn}$ respectively from an indoor cultivation system using piggery wastewater (García et al., 2017). Also, in fresh and anaerobically digested piggery wastewater were evaluated the removal efficiency of nitrogen by $C$. vulgaris, S. obliquus and aerobic bacteria, which results in the removal range of 58.2-94.8\% and 64.493.9\%, respectively (González-Fernández et al., 2011).

\subsection{Myco-algal consortia}

The microalgae-fungi consortia are naturally denominated as lichen, this association allows fungi to obtain nutrients and carbohydrates from the microalgae, meanwhile, fungi provide protective support to microalgae against abiotic stress (Shahid et al., 2020). Hence, the application of myco- algal consortia in wastewater treatment processes at a large scale is not strange because of the fungal capacity to form pellets that englobe microalgae acting as natural coagulants and therefore facilitating the harvesting of microalgae. Some studies have been developed in a mixed culture of $C$. vulgaris and Mucor indicus obtaining the assimilation of ammonia and nitrogen to almost undetectable levels in synthetic aquaculture wastewater (Barnharst et al., 2018). Another research where the co-cultivation of $C$. vulgaris and Ganoderma lucidum was performed, the assimilation of $\mathrm{TN}$, $\mathrm{TP}$, and COD concentration from swine wastewater were from $74 \%, 84 \%$, and $79 \%$ respectively (Guo et al., 2017).

\section{PHOTOBIOREACTORS FOR MicRoAlgal CULTIVATION IN WASTEWATER}

The wastewater treatment processes based on microalgae cultivation required specific conditions to operate in the best cost-effective and high efficiency; Many researchers (Ting et al., 2017; Li et al., 2019) have focused on the development of new methods that improve the pollutant removal from agro-industrial wastewater. According to microalgal cultivation, these methods can be classified into two main types: suspended systems and fixed systems.

\subsection{Suspended PBRs}

Suspended photobioreactors (PBRs) are the most common bioreactors used in large-scale microalgae wastewater treatment because of their simple construction and low investment costs; where microalgae cells can grow freely in the bioreactors, allowing the free movement of pollutants in the stream (Ting et al., 2017; Wollmann et al., 2019). The suspended systems include open ponds systems and closed systems; these are used mainly on treating wastewater with a high organic loading rate because the illumination applied onto the PBRs is easy to control (Ting et al., 2017).

\subsubsection{Open pond systems}

The open pond systems used for the treatment of wastewater based on microalgae cultivation are operated by batch experiments in big flasks with or without paddle wheels; open ponds without a paddle, raceway ponds, and high rate algal ponds are grouped into this system (Ting et al., 2017; Gupta et al., 2019). The high-rate algal pond (HRAP) is the most common open system based on raceway configuration where paddle wheels are installed for mixing the microalgae culture and prevent the precipitation of biomass; the depth of the channels should be kept a range between 0.2-0.4 $\mathrm{m}$ to ensure the light penetration ( $\mathrm{Li}$ et al., 2019). The system is supplemented by $\mathrm{CO}_{2}$ to keep the appropriate $\mathrm{C}: \mathrm{N}: \mathrm{P}$ ratio, regulate $\mathrm{pH}$ and promote biomass production (Ting et al., 2017).

\subsubsection{Closed systems}

Even though, the construction of these kinds of systems results in higher capital costs, it solves an important problem that open systems used to have, the risk of contamination. Thus, closed systems maintain the microalgae culture axenic, avoiding the colonization of other competitors over the waste stream (Gupta et al., 2019; Li et al., 2019). An 
advantage in the use of these methods is the implementation of different sources of light (artificial or sunlight) into the microalgae growth; meanwhile, the main disadvantage of applying this methodology is the low volume capacity of bioreactor to treat wastewater (Gupta et al., 2019). Transparent plastic or glass tubes, flasks, or cylinders are used as bioreactors for wastewater treatment because light penetrates easily into the dense microalgae culture, enhancing photosynthetic processes (Ting et al., 2017; Gupta et al., 2019). Magyar et al. (2021) studied the biodegradation process of synthetic and organic wastewater in an anaerobic tank reactor. Microalgae (Chlorella vulgaris) were utilized as a bioindicator for anaerobic digestion and monitoring of the fermentation process. It was found that the concentration of nutrients showed logarithmical tendencies and COD showed power tendency during the experiment. The extent and the direction of the changes were in correspondence with microalgae activity. Besides bioindication, the viability of the microalgae and the chlorophyll concentration were also assessed in such fermentation processes, since microalgae can be a potential source for biofuel production and a plant nutrient (Magyar et al., 2021).

According to the configuration of the bioreactors used for the wastewater treatment, closed systems can be divided into flat systems, tubular systems, plastic bag bioreactors, and cylinder PBRs.

\subsubsection{Flat systems}

Flat bioreactors are commonly used for treating low organic load streams which have low solid content, and therefore allow better penetration of light; it is a simple mechanism composed of two main components, the flat transparent bioreactor, and the supplementation system. The light intensity is a key factor for operating these kinds of systems: an inappropriate intensity could cause the shading effect that could affect the pollutant removal as well as biomass production. In that way, it should be considered that light intensity decreases exponentially from the reactor wall until achieving the cell concentration in the center of the flat transparent bioreactor (Ting et al., 2017).

\subsubsection{Tubular systems}

Tubular PBRs are the most commonly applied configuration used at large-scale with higher pollutants concentrations or organic load of wastewater in working volumes between 8380 liters (Ting et al., 2017; Li et al., 2019). They are made up of an array of straight and looped plastic or glass tubes that are arranged vertically, horizontally, or as a helical coil (Gupta et al., 2019); a tube diameter of 5-9 cm and optimal length from 100 to $150 \mathrm{~m}$ have been proved as the best arrangement to maintain suitable $\mathrm{O}_{2}, \mathrm{CO}_{2}$ concentration and $\mathrm{pH}$ value in the culture ( $\mathrm{Li}$ et al., 2019). Usually, microalgal monocultures are used to treat wastewater in these types of systems, being C. pyrenoidosa, C. sorokiniana, C. zofingiensis, Scenedemus obliquus, and Tetraselmis suecica the most common strains (Ting et al., 2017).

\subsubsection{Plastic bag bioreactors}

Plastic bags are the cheapest bioreactors with very effective pollutants removal, composed of threes parts: the plastic bags, the frame which is the support of the plastic bags, and the aeration system. The material, size, aeration type, mixing ways, and structure of the frame are the main aspects to take in mind when is designed a plastic bag bioreactor. There are two main types of systems, the vertical airlift bioreactor (where gas is pumped into the bags) and the seesaw plastic bag (where microalgae and liquid is mixed together on the seesaw) (Ting et al., 2017). A study showed the ammonia nitrogen, nitrate, and phosphorus removal of $91.8 \%, 54 \%$, and $65.4 \%$ respectively, in $20 \mathrm{~L}$ of piggery wastewater treated by Spirulina platensis (Wang et al., 2013).

\subsubsection{Cylinder PBR (Ting, 2019)}

Like its name indicate the configuration of this PBR is a plastic or glass cylinder, which is divided by the aeration system into bubbling and airlift style. The material used for the construction of the cylinder is fundamental to achieve an appropriate light penetration, the principal materials are transparent resin or borosilicate glass. The most common microalgae genera used in wastewater treatment by this system are Chlorella and Scenedesmus. Studies have found a TN, TP removal, and biomass production of 73.5\%, 100\%, and $66.94 \mathrm{mg} / \mathrm{L}$ per day respectively, confirming the appropriate removal content of wastewater (Ting et al., 2017).

\subsection{Fixed system}

Fixed systems are characterized because microalgae or microalgae-bacteria consortia cultivation is developed onto porous matrices, fibers, or specific surfaces; facilitating the posterior microalgae harvesting and metabolic conversion of wastewater components (Goncalves, 2017; Ting et al., 2017; Wollmann et al., 2019). Immobilized bioreactors, biofilm bioreactors, and microalgae membrane bioreactor can be grouped; however, low concentrations of TN, TP, and COD should be applied and appropriate illumination should consider when these systems are modeled (Ting et al., 2017).

\subsubsection{Immobilized microalgae beads}

This particular system is based on the immobilization of living microalgae cells into natural or artificial surfaces that prevent the mobilization of microalgae cells. The material used for immobilization could vary between several types of materials such as polyurethane, polyvinyl, acrylamide, resins, natural polymers from algal polysaccharides (alginate, agar, and agarose), or amino polysaccharides from chitin, chitosan, nylon, and cotton (Luo, 2017; Ting et al., 2017; Gupta et al., 2019). However, the material always must be hydrophilic to allow the diffusion of wastewater into the beads; there should be a balance between the thickness of the beads and cell density because the light shading effect could occur with high cellular density (Ting et al., 2017). The evaluation of the biomass production is difficult to carry out because microalgae are packed, notwithstanding microalgae can be harvested simply after 
the wastewater treatment process is performed (Gupta et al., 2019). The main microalgae strains used in these processes are Chlorella and Scenedesmus. There are four kinds of immobilized bioreactors systems, these are the fluidized bed bioreactor (FBR), packed bed bioreactor (PBR), parallel plate bioreactor (PPR), and airlift bioreactor (ALR).

\subsubsection{Biofilm PBRs}

Similar to the previous section, biofilm PBRs need a solid surface where microalgae could attach and grow on it; biomaterials or non-biomaterials could be used as supporting material in that way nylon and stainless mesh have been identified as the most preferable material for microalgae biofilm (Ting et al., 2017; Ting et al., 2017; Li et al., 2019). However, the microalgae biofilm is composed of a consortium of microorganisms such as microalgae, bacteria, or fungus which form a symbiotic relationship attached over the supporting material ( $\mathrm{Li}$ et al., 2019); meanwhile, wastewater is poured down through the biofilm (Ting et al., 2017). Because of the interaction between microalgae and bacteria, the $\mathrm{CO}_{2}$ and $\mathrm{O}_{2}$ supplementation to the medium is not needed (Ting et al., 2017); the biofilm formation enhances the nutrient recovery and heavy metal assimilation, facilitating the biomass production and posterior harvesting (Ting et al., 2017; Li et al., 2019). Studies have shown 2.8 times higher biomass productivity compared with suspended systems (Li et al., 2019). Some of the most common microalgae strains used in wastewater treatment are Chlorella, Scenedesmus, Pediastrum, Nitzschia, Cosmarium filamentous, and others; on different cultivation systems that could be classified as constantly submerged systems and intermittently submerged systems (Li et al., 2019).

A novel design of microalgae biofilm has been developed in wastewater treatment processes, called rotating algal biofilm reactor (RABR) which consists of cylinders where microalgae grow partly immersed into wastewater. The cylinders are rotating during the operation to ensure biofilms get exposed to both wastewater and air alternatively; this new configuration increase the nutrient removal rates for TP and $\mathrm{TN}$ in 2.1 and $14.1 \mathrm{~g} / \mathrm{m}^{2}$ per day, respectively (Ting et al., 2017; Li et al., 2019).

\subsubsection{Microalgae membrane bioreactors}

Membrane bioreactors are the most popular and effective wastewater treatment technology applied on waste streams which are composed of four main parts: the main reactor with cylinder, membrane module, light provision system, and gas supplementation system (Ting et al., 2017). The bioreactor surface is transparent to allow the penetration of light, the membrane module is always submerged into wastewater, the $\mathrm{CO}_{2}$ and air gas are pumped from the bottom of the bioreactor to provide a carbon source and adjust $\mathrm{pH}$ of the wastewater. The membrane module should be hydrophilic with a pore size range between 0.1 and 0.45 $\mu \mathrm{m}$ to achieve wastewater pass through the membrane. However, the hydraulic retention time (HRT) and solids retention time (SRT) are two factors that should be taken into account as well as the type of microalgae; the most common microalgae genera used in this kind of bioreactor are Chlorella and Scenedesmus, and even more important the application of microalgae-bacteria consortia cultivation (Luo et al., 2017; Ting et al., 2017; Li et al., 2019).

\section{HARVESTING METHODS FOR MICROALGAE RECOVERY}

The harvesting process consists of the detachment of algal biomass from the supporting media; an energy-intensive process due to the small size of microalgae cells $(2-200$ $\mu \mathrm{m})$, negative charge on the surface, and large volume of water handled (Rawat et al., 2013; Alam and Wang, 2019; Gupta et al., 2019). The major bottleneck process is considered in microalgae-based wastewater treatment and biodiesel production (Gupta et al., 2019); and can contribute to $20-30 \%$ of the total cost of biomass production (Rawat et al., 2013; Alam and Wang, 2019). Physical, chemical, and biological methods could be used for biomass recovery; however, the combination of multiple harvesting methods allows minimal energy consumption and cost-effective operation (Rawat et al., 2013; Gupta et al., 2019).

\subsection{Mechanical methods}

Several physical/mechanical methods have been used to harvest the algal biomass; however, the decision for the best technology depends on the characteristics of algae and their status on the supporting media (Alam and Wang, 2019). The main mechanical techniques for microalgal separation are gravity sedimentation, centrifugation, filtration, and flotation.

\subsubsection{Gravity sedimentation}

Sedimentation is the most common method used for the separation of larger microalgae from larger volumes of wastewater (Rawat et al., 2013). This technology is simple and cheap because the setting occurs on account of the size of the cells (Gupta et al., 2019); however, the sedimentation could be a very slow process $(0.1-2.6 \mathrm{~cm} / \mathrm{h})$ and could cause the deterioration of the biomass due to high temperature (Rawat et al., 2013; Alam and Wang, 2019). The harvesting of larger microalgae genera like Spirulina, Micractinim, some species of Scenedesmus, and Cyclotella are frequently processed (Gupta et al., 2019).

\subsubsection{Centrifugation}

Centrifugation is the most desired method due to the short recovery time and efficiency. Higher than $90 \%$ of microalgal biomass is harvested in 2-5 min at 500-1000 rpm (Alam and Wang, 2019). It consists of a centripetal force that separates microalgal biomass from the media in a centrifuge; several types of centrifuges like continuous flow, spiral plate, nozzle discharge, self-cleaning disc stack have been applied on the harvesting of Scenedesmus, Coelastrum proboscideum, Artrosphira platensis at lab-scale (Rawat et al., 2013; Gupta et al., 2019). However, its application at large-scale requires highly intensive energy consumption and thence high operational cost (Gupta et al., 2019). 


\subsubsection{Filtration}

Filtration consists of the separation of microalgal biomass through the use of a porous membrane that retains the microalgae slurry, meanwhile, the remaining wastewater is deposited (Gupta et al., 2019). This strategy could be ideal for the separation of larger microalgae cells like Coelastrum proboscideum and Spirulina platensis; however, its application on harvesting smaller microalgae cells like Chlorella, Scenedesmus, and Dunallella results difficult to process because of membrane fouling (Rawat et al., 2013; Gupta et al., 2019). Due to the membrane fouling, regular membrane replacement is necessary; increasing the operational costs and thus, making its application not frequent at large-scale processes (Rawat et al., 2013; Alam and Wang, 2019; Gupta et al., 2019). However, several strategies have been developed to solve this problem, resulting in different filtration methods like ultrafiltration, microfiltration, vacuum filtration, pressure filtration, deadend filtration, membrane filtration, and reverse osmosis (Alam and Wang, 2019; Gupta et al., 2019). Ultrafiltration or microfiltration are expensive technologies because they require regular membrane replacements and high energy demand (Alam and Wang, 2019). Pressure filtration is more efficient than vacuum filtration collecting microalgae cells despite the intensive energy demand of both systems (Rawat et al., 2013).

\subsubsection{Flotation}

Flotation is one of the most commonly used methods which consists of introducing air or gas bubbles into the floatation tank; microalgae cells are attached to the bubbles which rise to the top and get concentrated on the surface (Gupta et al., 2019; Al-Jabri et al., 2021). Therefore, this technology has several advantages such as short operation time, less area requirement, can be easily scaled-up, and provides $50-90 \%$ recovery of biomass (Gupta et al., 2019). Currently, four flotation techniques are known: dissolved air flotation (DAF), dispersed air flotation, electrolytic flotation, and ozonation-dispersed flotation (ODF). The first two technologies vary in the form of air supplementation, the third technology is based on the generation of hydrogen bubbles by electrolysis, and ozone supplementation replaced the air in the last technology (Alam and Wang, 2019; Gupta et al., 2019). Thus, bubbles' size is an important factor to obtain higher removal efficiency, smaller size shows better results (Al-Jabri et al., 2021).

\subsection{Chemical methods}

Harvesting biomass of microalgae-based on chemical methods uses flocculant agents to achieve the aggregation of microalgae cells (coagulation) and posterior settle down (AlJabri et al., 2021). This technology works in a simple way because the microalgae cell-surface has negative charge, small size $(<15 \mu \mathrm{m})$, and marginally higher density than water (Rawat et al., 2013; Gupta et al., 2019). The negative charge of microalgae cell-surface could be neutralized by the utilization of multivalent organic or inorganic cations (coagulation-flocculation), or the increase of $\mathrm{pH}$ media above 8.5, causing the so-called auto-flocculation (Rawat et al., 2013; Al-Jabri et al., 2021). Inorganic cations are the most frequent flocculant agents used to treat wastewater effluents (Rawat et al., 2013); inside this group is possible to find several multivalent metal salts like aluminum sulfate, ferric sulfate, and ferric chloride (Gupta et al., 2019; AlJabri et al., 2021). However, their application should be carried out carefully because of the toxic effect on microalgae biomass or possible environmental contamination by metal salts (Gupta et al., 2019). On the other hand, the application of organic natural polymers (chitosan, tannin, starch, glutamic acid) or synthetic polymers (Flocudex CS/5000, Chemifloc CV/300, Drewfloc 447) have been studied in the last decades, obtaining better harvesting efficiency (20-100\%) with low dosage requirement $(5-100 \mathrm{mg} / \mathrm{L})$; furthermore, non-toxic effects or contamination have been reported (Rawat et al., 2013; Gupta et al., 2019; Al-Jabri et al., 2021). The use of electrodes connected to a DC power has been developed to achieve the flocculation of microalgae biomass in the socalled electrocoagulation process; a recovery efficiency of 93.6\% after 30 min by electrocoagulation and $98.9 \%$ after $14 \mathrm{~min}$ by electrocoagulation integrated in a dispersed-air flotation have been reported (Rawat et al., 2013; Al-Jabri et al., 2021).

\subsection{Biological methods}

The so-called auto-flocculation and bio-flocculation processes are integrated inside this category; both are characterized due to the use of microalgae consortia and the pH adjustment of the media (Rawat et al., 2013; Gupta et al., 2019; Al-Jabri et al., 2021). The auto-flocculation could result from the interaction of microalgae strains who can form flocs like some filamentous cyanobacteria such as Phormidium sp., Leptolyngbya sp., Pseudoanabaena sp. (Al-Jabri et al., 2021); or on the other side, the $\mathrm{pH}$ adjustment of media to alkaline conditions (above 8.5) which leads the precipitation of excess calcium or magnesium ions as phosphates on the microalgae (Rawat et al., 2013; Gupta et al., 2019). The bio-flocculation results from the interaction of microalgae consortia cultivation like myco-algal consortium which can form pellets that accelerate the biomass harvesting, or by microalgae-bacteria consortium which forms bio-flocs that improves harvesting efficiency (Gupta et al., 2019; Al-Jabri et al., 2021). A study demonstrated a flocculating activity of $92.0 \pm 6.0 \%$ in the cocultivation of $C$. vulgaris and aerobic bacteria in untreated seafood wastewater, obtaining total suspended solids removal of $93.0 \pm 5.5 \%$, and nutrient removal of $88.0 \pm 2.2 \%$. The bio-flocs collected contained dry matter of $107.2 \pm 5.6$ $\mathrm{g} / \mathrm{L}$ and chlorophyll content of $25.5 \pm 0.2 \mathrm{mg} / \mathrm{L}$ (Dong et al., 2019).

\section{CONCLUSIONS}

The rising global demand for food and energy, and the increasing wastewater generation from agro-industrial activities demand the development of sustainable strategies for the mitigation of highly pollutant streams. Thereby, the microalgae-based wastewater treatment process is established as an eco-friendly solution where natural processes from microalgae are used to achieve the removal 
of minerals or heavy metals; meanwhile, biomass production could be used as a potentially renewable resource for energy. According to Magyar et al. (2021), pH has a significant effect on the microalgae cultivation (chlorophyll concentration and microalgae activity rate). The Chlorella vulgaris is applicable to track the biodegradation processes as a bioindicator. Moreover, a strong correlation was found between the concentration of nutrients and the microalgae activity rate, if appropriate amounts of nutrients are available for their growth. Otherwise, the microalgae are involved in the fermentation process as a substrate slightly increasing the concentration of some nutrients in the wastewater (Magyar et al., 2021). However, removal efficiency depends on many factors since the selection of the microalgae strain or microalgae consortia to be cultivated. Furthermore, the type and characteristics of wastewater used as source media that microalgae need to survive under these conditions. Due to the above-mentioned, microalgae cultivation is not an option for the treatment of municipal wastewaters, because the toxic contaminants and heterogeneous conditions could inhibit the microalgae growth.

In this review, some actual features were summarized that have been developed in the last decade to improve the removal efficiency of biological treatment from agroindustrial wastewaters.

\section{ACKNOWLEDGMENT}

The work/publication is supported by the EFOP-3.6.1-162016-00022 project and the Thematic Excellence Programme of the Ministry for Innovation and Technology in Hungary (ED_18-1-2019-0028), within the framework of the Space Sciences thematic programme of the University of Debrecen.

\section{REFERENCES}

Al-Jabri, H., Das, P., Khan, S., Thaher, M., and Abdulquadir, M. (2021). Treatment of wastewaters by microalgae and the potential applications of the produced biomass - a review. Water (Switzerland) 13, 1-26.

DOI: $10.3390 / \mathrm{w} 13010027$.

Al Darmaki, A., Govindrajan, L., Talebi, S., Al-Rajhi, S., Al-Barwani, T., and Al-Bulashi, Z. (2012). Cultivation and characterization of microalgae for wastewater treatment. Lect. Notes Eng. Comput. Sci. 2197, 599-602.

Alam, M. A., and Wang, Z. (2019). Microalgae biotechnology for development of biofuel and wastewater treatment.

DOI:10.1007/978-981-13-2264-8.

Avula, R. Y., Nelson, H. M., and Singh, R. K. (2009). Recycling of poultry process wastewater by ultrafiltration. Innov. Food Sci. Emerg. Technol. 10, 1-8.

DOI:10.1016/j.ifset.2008.08.005.
Barnharst, T., Rajendran, A., and Hu, B. (2018). Bioremediation of synthetic intensive aquaculture wastewater by a novel feed-grade composite bio film. Int Biodeterior Biodegradation 126, 131-142.

DOI:10.1016/j.ibiod.2017.10.007.

Brantes, L., Mendes, B., and Vermelho, A. B. (2013). Allelopathy as a potential strategy to improve microalgae cultivation. Biotechnol. for Biofuels 6, 1-14.

Caporgno, M. P., Taleb, A., Olkiewicz, M., Font, J., Pruvost, J., Legrand, J., et al. (2015). Microalgae cultivation in urban wastewater: Nutrient removal and biomass production for biodiesel and methane. Algal Res. 10, 232239.

DOI:10.1016/j.algal.2015.05.011.

Cheah, W. Y., Ling, C., Loke Show, P., Juan, J. C., Chang, J.-S., and Lee, D.-J. (2016). Cultivation in wastewaters for energy: A microalgae platform. Appl. Energy 179, 609-625. DOI:10.1016/j.apenergy.2016.07.015.

Chen, L., Wei, J., Wang, W., and Wang, C. (2013). Combination of microalgae cultivation with membrane processes for the treatment of municipal wastewater. Water Sci. Technol. 68, 2374-2381.

DOI: 10.2166/wst.2013.509.

Chiu, S.-Y., Kao, C.-Y., Chen, T.-Y., Chang, Y.-B., Kuo, C.-M., and Lin, C.-S. (2014). Cultivation of microalgal Chlorella for biomass and lipid production using wastewater as nutrient resource. Bioresour. Technol. 184, 179-189.

DOI:10.1016/j.biortech.2014.11.080.

De Freitas Coêlho, D., Tundisi, L. L., Santos Cerqueira, K., Rego, J., Rodrigues, S., Gava Mazzola, P., et al. (2019). Microalgae: Cultivation Aspects and Bioactive Compounds. Brazilian Arch. Biol. Technol. 62, 19180343. DOI: $10.1590 / 1678-4324-2019180343$.

Dong, T., Nguyen, P., Van, T., Le, A., Loke Show, P., Nguyen, T. T., et al. (2019). Bioflocculation formation of microalgae-bacteria in enhancing microalgae harvesting and nutrient removal from wastewater effluent. Bioresour. Technol. 272, 34-39.

DOI:10.1016/j.biortech.2018.09.146.

García, D., Posadas, E., Grajeda, C., Blanco, S., Martínezpáramo, S., Acién, G., et al. (2017). Comparative evaluation of piggery wastewater treatment in algal-bacterial photobioreactors under indoor and outdoor conditions. Bioresour. Technol. 245, 483-490.

DOI:10.1016/j.biortech.2017.08.135.

Gonçalves, A. L., Pires, J. C. M., and Simões, M. (2017). A review on the use of microalgal consortia for wastewater treatment. Algal Res. 24, 403-415.

DOI:10.1016/j.algal.2016.11.008. 
González-Fernández, C., Molinuevo-Salces, B., and GarcíaGonzález, M. C. (2011). Nitrogen transformations under different conditions in open ponds by means of microalgae bacteria consortium treating pig slurry. Biomass and Bioenergy 102, 960-966.

DOI: 10.1016/j.biortech.2010.09.052.

Guldhe, A., Ansari, F. A., Singh, P., and Bux, F. (2017). Heterotrophic cultivation of microalgae using aquaculture wastewater: A biorefinery concept for biomass production and nutrient remediation. Ecol. Eng. 99, 47-53.

DOI: 10.1016/j.ecoleng.2016.11.013.

Guo, G., Cao, W., Sun, S., Zhao, Y., and Hu, C. (2017). Nutrient removal and biogas upgrading by integrating fungal - microalgal cultivation with anaerobically digested swine wastewater treatment. J. Appl. Phycol. 29, 2857-2866.

DOI: $10.1007 / \mathrm{s} 10811-017-1207-2$.

Guo, Z., Liu, Y., Guo, H., Yan, S., and Mu, J. (2013). Microalgae cultivation using an aquaculture wastewater as growth medium for biomass and biofuel production. J. Environ. Sci. 25, S85-S88.

DOI: $10.1016 / \mathrm{S} 1001-0742(14) 60632-\mathrm{X}$.

Gupta, S., Pawar, S. B., and Pandey, R. A. (2019). Current practices and challenges in using microalgae for treatment of nutrient rich wastewater from agro-based industries. Sci. Total Environ. J. 687, 1107-1126.

DOI:10.1016/j.scitotenv.2019.06.115.

Hawrot-Paw, M., Koniuszy, A., Gałczynska, M., Zajac, G., and Szyszlak-Bargłowicz, J. (2020). Production of microalgal biomass using aquaculture wastewater as growth medium. Water (Switzerland) 12.

DOI: $10.3390 /$ w12010106.

Hussain, F., Shah, S. Z., Ahmad, H., Abubshait, S. A., Abubshait, H. A., Laref, A., et al. (2021). Microalgae an ecofriendly and sustainable wastewater treatment option: Biomass application in biofuel and bio-fertilizer production. A review. Renew. Sustain. Energy Rev. 137, 1-10. DOI:10.1016/j.rser.2020.110603.

Huy, M., Kumar, G., Kim, H., and Kim, S. (2018). Photoautotrophic cultivation of mixed microalgae consortia using various organic waste streams towards remediation and resource recovery. Bioresour. Technol. 247, 576-581. DOI:10.1016/j.biortech.2017.09.108.

Khan, M. I., Shin, J. H., and Kim, J. D. (2018). The promising future of microalgae: current status, challenges, and optimization of a sustainable and renewable industry for biofuels, feed, and other products. Microb. Cell Fact. 17, 36. DOI: $\underline{10.1186 / \mathrm{s} 12934-018-0879-\mathrm{x}}$.

Komolafe, O., Velasquez Orta, S. B., Monje-Ramirez, I., Yáñez Noguez, I., Harvey, A. P., and Orta Ledesma, M. T. (2014). Biodiesel production from indigenous microalgae grown in wastewater. Bioresour. Technol. 154, 297-304. DOI:10.1016/j.biortech.2013.12.048.

Koreiviené, J., Valciukas, R., Karosiené, J., and Baltrénas, P. (2014). Testing of Chlorella / Scenedesmus microalgae consortia for remediation of wastewater, $\mathrm{CO} 2$ mitigation and algae biomass feasibility for lipid production. J. Environ. Eng. Landsc. Manag. 22, 105-114.

DOI: $10.3846 / 16486897.2013 .911182$.

Li, K., Liu, Q., Fang, F., Luo, R., Lu, Q., Zhou, W., et al. (2019). Microalgae-based wastewater treatment for nutrients recovery: A review. Bioresour. Technol. 291, 1-16. DOI: 10.1016/j.biortech.2019.121934.

Li, X., Wu, S., Yang, C., and Zeng, G. (2020). Microalgal and duckweed based constructed wetlands for swine wastewater treatment: A review. Bioresour. Technol. 318, 123858. DOI:10.1016/j.biortech.2020.123858.

Li, Y. Xia, Li, W., Wu, J., Xu, L. Chao, Su, Q. Hong, and Xiong, X. (2007). Contribution of additives $\mathrm{Cu}$ to its accumulation in pig feces: study in Beijing and Fuxin of China. J. Environ. Sci. 19, 610-615.

DOI: $\underline{10.1016 / \text { S1001-0742(07)60101-6. }}$.

Lowrey, J., Brooks, M. S., and Mcginn, P. J. (2015). Heterotrophic and mixotrophic cultivation of microalgae for biodiesel production in agricultural wastewaters and associated challenges-a critical review. J. Appl. Phycol. 27, 1485-1498.

DOI: $10.1007 / \mathrm{s} 10811-014-0459-3$.

Luo, Y., Le-Clech, P., and Henderson, R. K. (2017). Simultaneous microalgae cultivation and wastewater treatment in submerged membrane photobioreactors: A review. Algal Res. 24, 425-437.

DOI:10.1016/j.algal.2016.10.026.

Magyar, T., Werle Vogel, F., Tóth, F., Nagy, A., Tamás, J. and Nagy, P. T. (2021). Characterization of the biodegradation of synthetic and organic wastewater in an anaerobic tank reactor using microalgae. Int. Rev. Appl. Sci. Eng. 12 (2), 166-175.

DOI: $10.1556 \% 2 \mathrm{~F} 1848.2021 .00217$

Maulana, M., Nur, A., and Buma, A. G. J. (2019). Opportunities and Challenges of Microalgal Cultivation on Wastewater, with Special Focus on Palm Oil Mill Effluent and the Production of High Value Compounds. Waste and Biomass Valorization 10, 2079-2097.

DOI: $10.1007 / \mathrm{s} 12649-018-0256-3$.

Molinuevo-Salces, B., Riaño, B., Hernández, D., and García-González, M. C. (2019). Microalgae and wastewater treatment: Advantages and disadvantages. Microalgae Biotechnol. Dev. Biofuel Wastewater Treat., 505-533.

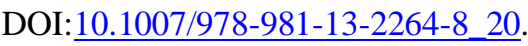


Nagarajan, D., Kusmayadi, A., Yen, H. W., Dong, C. Di, Lee, D. J., and Chang, J. S. (2019). Current advances in biological swine wastewater treatment using microalgaebased processes. Bioresour. Technol. 289, 121718.

DOI:10.1016/j.biortech.2019.121718.

Nguyen, M.-L. T., Lin, C.-Y., and Lay, C.-H. (2019). Microalgae cultivation using biogas and digestate carbon sources. Biomass and Bioenergy 122, 426-432.

DOI: 10.1016/j.biombioe.2019.01.050.

Novoveská, L., Zapata, A. K. M., Zabolotney, J. B., Atwood, M. C., and Sundstrom, E. R. (2016). Optimizing microalgae cultivation and wastewater treatment in largescale offshore photobioreactors. Algal Res. 18, 86-94.

DOI: 10.1016/j.algal.2016.05.033.

Paddock, M. B., Dionisio Fernández-Bayo, J., and Vandergheynst, J. S. (2020). The effect of the microalgaebacteria microbiome on wastewater treatment and biomass production. Environ. Biotechnol. 104, 893-905.

DOI: $\underline{10.1007 / \mathrm{s} 00253-019-10246-\mathrm{X}}$.

Posadas, E., Alcá, C., García-Encina, P. A., Gouveia, L., Guieysse, B., Norvill, Z., et al. (2017). Microalgae cultivation in wastewater. Microalgae-Based Biofuels Bioprod., 67-91.

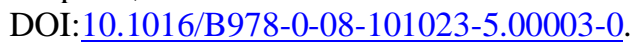

Rawat, I., Ranjith Kumar, R., Mutanda, T., and Bux, F. (2013). Biodiesel from microalgae: A critical evaluation from laboratory to large scale production. Appl. Energy 103, 444-467.

DOI:10.1016/j.apenergy.2012.10.004.

Roser, M., Ritchie, H., and Ortiz-Ospina, E. (2019). World Population Growth: Two centuries of rapid global population growth will come to an end. Our World In Data. Available at:

https://ourworldindata.org/world-population-growth\#twocenturies-of-rapid-global-population-growth-will-come-toan-end [Accessed November 8, 2021].

Sandefur, H. N., Asgharpour, M., Mariott, J., Gottberg, E., Vaden, J., Matlock, M., et al. (2016). Recovery of nutrients from swine wastewater using ultrafiltration: Applications for microalgae cultivation in photobioreactors. Ecol. Eng. 94, $75-81$.

DOI: 10.1016/j.ecoleng.2016.05.066.

Shahid, A., Malik, S., Zhu, H., Xu, J., Zohaib Nawaz, M., Nawaz, S., et al. (2020). Cultivating microalgae in wastewater for biomass production, pollutant removal, and atmospheric carbon mitigation; a review. Sci. Total Environ. 704, 1-17.

DOI:10.1016/j.scitotenv.2019.135303.

Shchegolkova, N., Shurshin, K., Pogosyan, S., Voronova, E., Matorin, D., and Karyakin, D. (2018). Microalgae cultivation for wastewater treatment and biogas production at Moscow wastewater treatment plant. Water Sci. Technol. $78,69-80$.

DOI: $10.2166 /$ wst.2018.088.

Singh, M., Reynolds, D. L., and Das, K. C. (2011). Microalgal system for treatment of effluent from poultry litter anaerobic digestion. Bioresour. Technol. 102, 1084110848.

DOI: $\underline{10.1016 / j . b i o r t e c h .2011 .09 .037 . ~}$

Terán Hilares, R., Garcia Bustos, K. A., Sanchez Vera, F. P., Colina Andrade, G. J., and Pacheco Tanaka, D. A. (2021). Acid precipitation followed by microalgae (Chlorella vulgaris) cultivation as a new approach for poultry slaughterhouse wastewater treatment. Bioresour. Technol. 335.

DOI:10.1016/j.biortech.2021.125284.

Ting, H., Haifeng, L., Shanshan, M., Zhang, Y., Zhidan, L., and Na, D. (2017). Progress in microalgae cultivation photobioreactors and applications in wastewater treatment: A review. Int. J. Agric. Biol. Eng. 10, 1-29.

DOI: $\underline{10.3965 / j . i j a b e .20171001 .2705}$.

Umamaheswari, J Shanthakumar, S. (2016). Efficacy of microalgae for industrial wastewater treatment: a review on operating conditions, treatment efficiency and biomass productivity. Rev. Environ. Sci. Bio/Technology 15, 265284.

DOI: $10.1007 / \mathrm{s} 11157-016-9397-7$.

United Nations, Department of Economics and Social Fairs, and Population Division (2019). World Population Prospects 2019: Highlights. New York Available at: https://population.un.org/wpp/Publications/Files/WPP2019_ Highlights.pdf [Accessed November 8, 2021].

Wang, M., Yang, Y., Chen, Z., Chen, Y., Wen, Y., and Chen, B. (2016). Removal of nutrients from undiluted anaerobically treated piggery wastewater by improved microalgae. Bioresour. Technol. 222, 130-138.

DOI:10.1016/j.biortech.2016.09.128.

Wang, T. Y., Liu, H. C., and Lee, Y. (2013). Use of Anthropic Acclimated Spirulina platensis (Arthrospira platensis) Bio-adsorption in the Treatment of Swine Farm Wastewater. Int. J. Agric. Biol. 15: 107-112.

Wollmann, F., Dietze, S., Ackermann, J. U., Bley, T., Walther, T., Steingroewer, J., et al. (2019). Microalgae wastewater treatment: Biological and technological approaches. Eng. Life Sci. 19, 860-871.

DOI: 10.1002/ELSC.201900071.

Zabed, H. M., Akter, S., Yun, J., Zhang, G., Zhang, Y., and Qi, X. (2020). Biogas from microalgae: Technologies, challenges and opportunities. Renew. Sustain. Energy Rev. 117, 109503.

DOI: $\underline{10.1016 / \text { j.rser.2019.109503. }}$. 
Zhang, D., Wang, X., and Zhou, Z. (2017). Impacts of small-scale industrialized swine farming on local soil, water and crop qualities in a hilly red soil region of subtropical China. Int. J. Environ. Res. Public Health 14(2) 1524. DOI:10.3390/ijerph14121524. the Creative Commons Attribution (CC BY) licence (http://creativecommons.org/licenses/by/4.0/). 